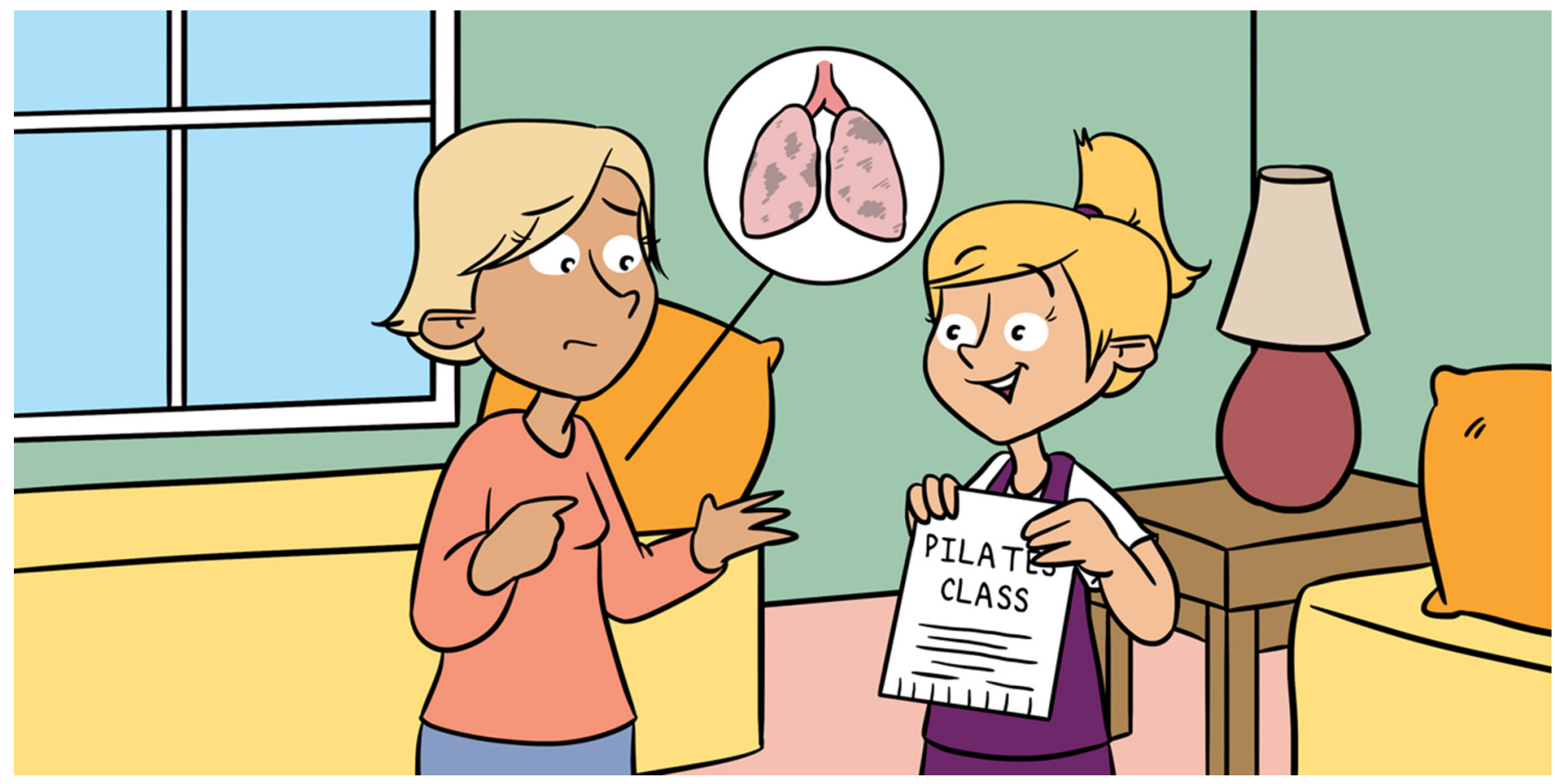

\title{
WHAT HAPPENS TO THE LUNGS WHEN THEY GET HURT?
}

\section{Alexandra Jacqueline Boni ${ }^{1 *}$, Willy Roque ${ }^{2}$ and Freddy Romero ${ }^{3}$}

${ }^{1}$ New Jersey Medical School, Rutgers, The State University of New Jersey, Newark, NJ, United States

${ }^{2}$ Department of Medicine, New Jersey Medical School, Rutgers, The State University of New Jersey, Newark, NJ, United States ${ }^{3}$ Baylor College of Medicine, Houston, TX, United States

\section{YOUNG REVIEWERS:}

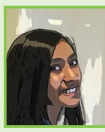

NITYA

AGE: 10

SIDHAARTH

AGE: 14
Lung fibrosis is a lung disease that primarily affects older adults and makes it hard to breathe. The lungs get scarred and thick from inflammation, so exchange of oxygen and carbon dioxide is impaired. In this article, you will first learn how the lungs allow us to breathe and why we must breathe in the first place. You will also learn what causes lung fibrosis, its symptoms, how doctors diagnose it, and the ways to treat it. You will learn that there is no cure, but that means that maybe 1 day you can discover the cure!

\section{WHAT DO THE LUNGS DO, AND WHY DO YOU HAVE TO BREATHE?}

The lungs are the main organs that allow us to breathe. Breathing is necessary for life because it brings oxygen into our bodies and lets carbon dioxide leave our bodies. Oxygen is necessary for many different essential processes that take place inside the body's cells, 
Figure 1

Lung anatomy and gas exchange in healthy and fibrotic lungs. Air travels from the trachea to bronchi, which branch into bronchioles. At the end of bronchioles there are alveoli, the site of gas exchange. (A) In healthy lungs, exchange of oxygen and carbon dioxide occurs easily across the thin wall of the alveoli.

(B) In the lungs of a person with lung fibrosis, gas exchange is not as efficient because the gases have a much further distance to travel through the thick alveolar walls.

\section{ALVEOLI}

The smallest structures of the lungs, where gas exchange occurs.

\section{GAS EXCHANGE}

The process of exchanging oxygen and carbon dioxide between the alveoli and capillaries in the lungs.

\section{CAPILLARY}

The smallest blood vessels in the body, which have extremely thin walls that allow for the exchange of materials like gases.

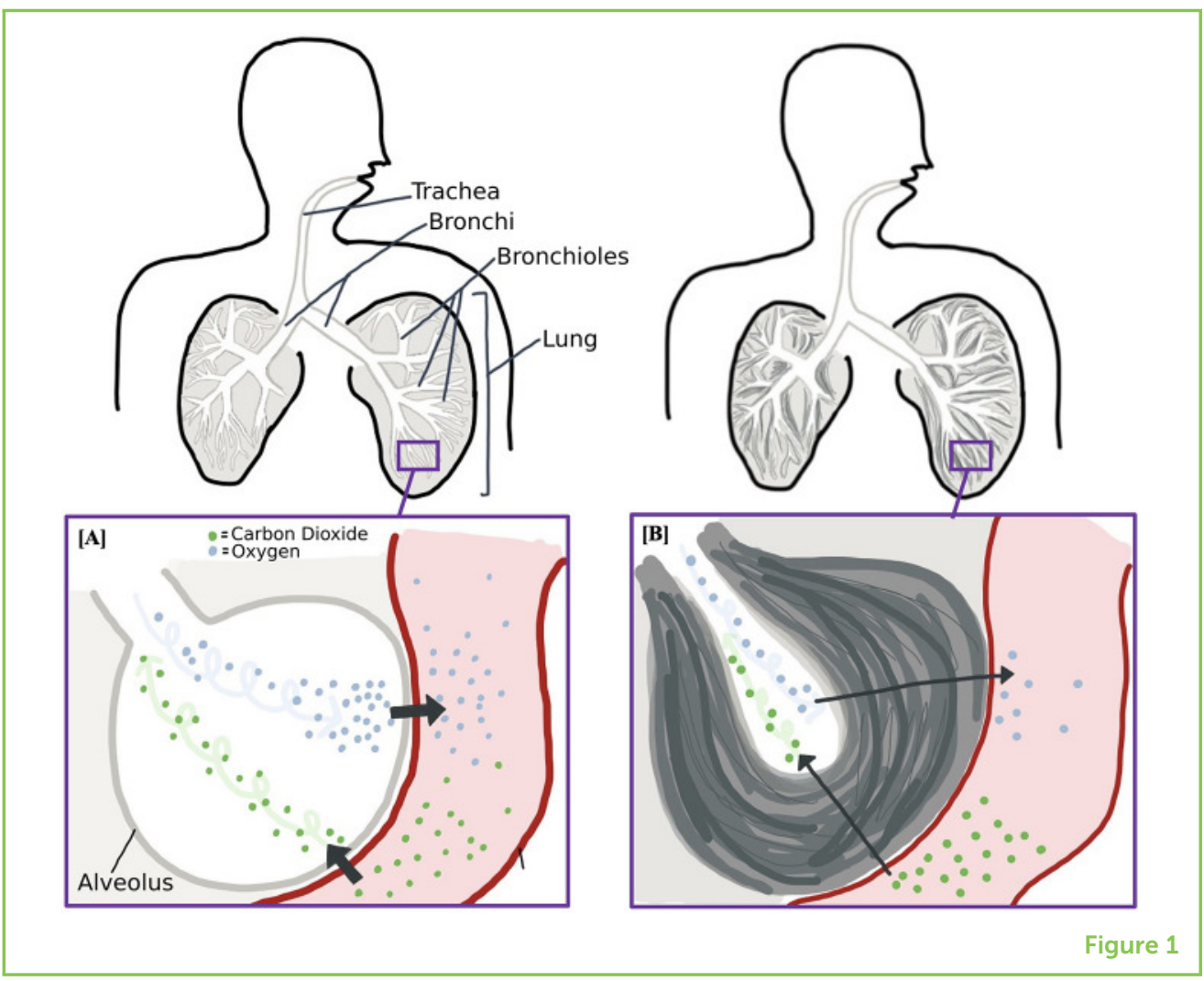

including generating energy. Without oxygen, we would not be able to run, play, or even think! Carbon dioxide is a gas that is generated as a waste product when cells make energy, and it is toxic if it stays inside the body for too long.

When we inhale, air comes in through the mouth and nose, into the throat, and into the lungs through a series of tubes. When air gets to the lungs, it travels through smaller and smaller tubes, called bronchi and bronchioles, that end in alveoli. Alveoli are small sacs of very thin tissue that allow for gas exchange (Figure 1A). Gas exchange means that oxygen gas is swapped for carbon dioxide gas: oxygen moves out of the lungs and into the blood, while carbon dioxide moves out of the blood and into the lungs. Gas exchange is possible because the alveoli are located next to very small blood vessels called capillaries. Both the alveoli and capillaries are extremely thin, so the tiny molecules of oxygen and carbon dioxide can easily travel between them. Oxygen travels in the blood through the capillaries of the lungs and into the vessels of the heart, where the oxygen-rich blood is then pumped through arteries to the rest of the body. The carbon dioxide moves back through the alveoli, up the bronchioles and bronchi, up the throat, and out of the mouth and nose as we exhale. 


\section{FIBROSIS}

The abnormal healing process that creates scars, or thick collections of collagen proteins, when fibroblasts over-respond to inflammatory signals.

\section{CHRONIC}

Something that is present for a long time, that does not go away quickly. Constant.

\section{INFLAMMATION}

A result of activation of the immune system, which usually happens only in response to an infection, but sometimes (like in lung fibrosis) occurs when there is no infection.

\section{PNEUMOCYTE}

The individual cells that form alveoli. They send out inflammatory signals when they are damaged.

\section{FIBROBLAST}

A cell that makes collagen as part of the normal response to inflammatory signals sent from damaged cells. Fibroblasts are present throughout the body.

\section{WHAT IS LUNG FIBROSIS?}

Lung fibrosis is a type of chronic lung disease that makes it hard for people to breathe. Chronic means that this disease takes a long time to develop and slowly gets worse the longer a person has it. Adults over the age of 50 are usually the only people who get lung fibrosis [1]. When someone has lung fibrosis, the alveoli are scarred and thick from inflammation. Since gas exchange happens best when the alveoli are thin, when there is fibrosis less oxygen can travel through the thick alveoli, so less oxygen gets into the body with every breath (Figure 1B).

\section{WHAT CAUSES LUNG FIBROSIS?}

There are many causes of lung fibrosis because there are many ways that the lungs can get scarred. Breathing in certain very small dust particles, such as sand dust or coal dust, can irritate the lungs, so people whose jobs include sand blasting or coal mining are at a higher risk for developing lung fibrosis. The small dust particles get into the alveoli and start an immune response that causes inflammation, and the inflammation leads to scars. Specifically, the cells that make up the alveoli (called pneumocytes) get damaged and send signals that start the inflammation process. Cells called fibroblasts are activated by the signals and overproduce collagen, a stiff protein that makes scars (Figure 2).

Treatments for certain diseases can cause lung fibrosis, too. These include chemotherapy medication and radiation therapy used to treat cancer, and certain medicines for the heart. However, most cases of lung fibrosis are idiopathic, which means that we do not know exactly what causes them. Lung fibrosis is more common in people who have a relative with lung fibrosis, and there are some genes that are known to give people a predisposition toward developing the disease. The theory is that, in people who are predisposed to developing lung fibrosis, the immune system creates inflammation all the time, even when no foreign materials or organisms are present. The lungs get scarred from all the extra inflammation [2].

\section{WHAT ARE THE SYMPTOMS OF LUNG FIBROSIS?}

The main symptoms of lung fibrosis are shortness of breath, cough, and fatigue. People with lung fibrosis have a hard time taking deep breaths and normal activities make them feel extremely tired. They also cannot exercise because, as we learned earlier, less oxygen gets into the body with every breath, due to the thick alveoli. Sometimes, people with lung fibrosis also lose weight and have tired muscles and joints because, without oxygen, they cannot make enough energy to keep the body going. 
Figure 2

The alveoli of healthy and fibrotic lungs. (A) In healthy lungs, the alveoli and capillaries are right next to each other in close proximity. Fibroblasts are also present as part of the normal architecture, producing collagen as part of the normal inflammatory response that occurs when cells are damaged. (B) In fibrotic lungs, pneumocytes are repeatedly damaged over and over again. They produce a lot of inflammatory signals, and in response the fibroblasts over-produce collagen. This collagen forms scar tissue, which makes a thick wall separating the alveoli and capillaries.
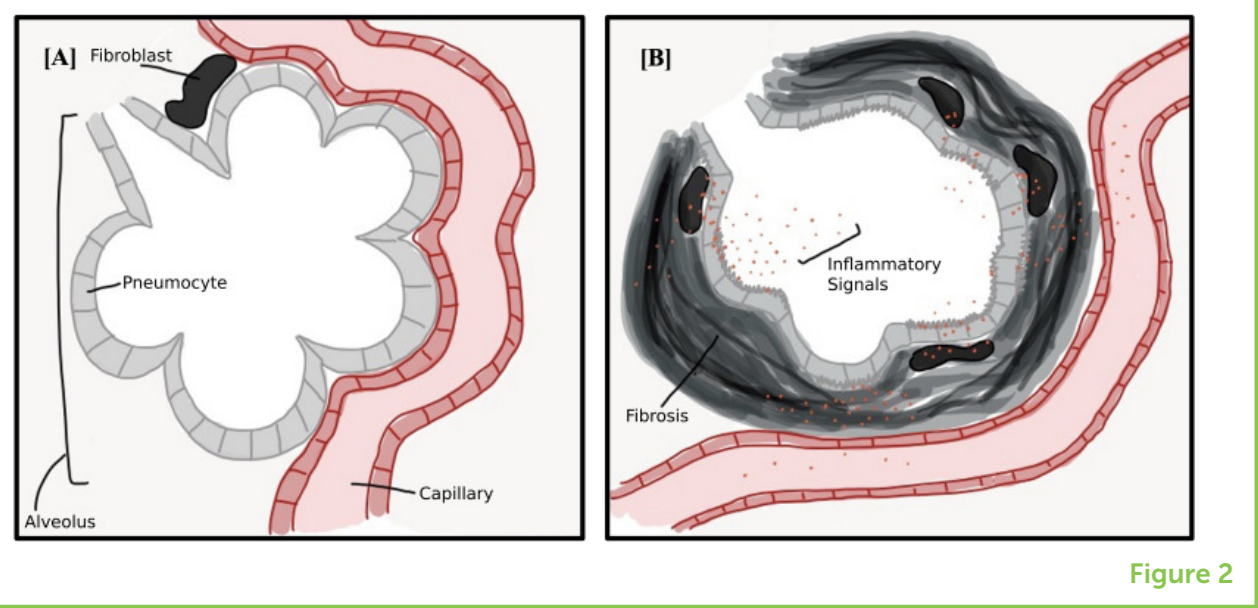

If a person has all the symptoms of lung fibrosis, a doctor can do tests to confirm the diagnosis. To diagnose lung fibrosis, doctors use a machine called a CT scanner to take pictures of the lungs. The pictures from the scanner allow doctors to see the scars and inflammation in the lungs. Sometimes, the doctor will have to biopsy the lungs if the pictures from the CT scanner are not clear. In these cases, the doctor will take a little piece of the lung tissue and look at it under a microscope, where it is easier to see the scars and cells that cause inflammation.

\section{HOW IS LUNG FIBROSIS TREATED?}

Unfortunately, there is not a cure for lung fibrosis. There is no medication or procedure that will make the lung fibrosis go away forever, but there are interventions that can help. The first thing that can help patients is to stop smoking, because smoking also causes damage to the alveoli. There are some medical treatments that can help make a person with lung fibrosis feel more comfortable and breathe more easily. One of those is called pulmonary (lung) rehabilitation. When a patient goes to pulmonary rehabilitation, trained therapists help them exercise and teach them breathing techniques. Some medications can also make breathing easier by decreasing the inflammation that causes scarring in the lungs, but those treatments do not always work. If a person's lung fibrosis does not get better from rehab or medications, a lung transplant is the last treatment that is possible. A lung transplant is a surgery in which a patient's lungs are replaced with lungs from an organ donor. This is a very difficult surgery, and it takes a long time for the patient to recover.

\section{CONCLUSION}

During gas exchange, an essential bodily process that takes place in the lungs, oxygen is switched for carbon dioxide. The very close 
physical space between the alveoli and capillaries of the lungs allows gas exchange to occur easily. In lung fibrosis, gas exchange is impaired because scar tissue that is produced in response to lung damage makes a physical barrier in between the alveoli and capillaries. This makes people short of breath and unable to exercise. There are a lot of researchers working to better understanding lung fibrosis and searching for new treatments, but unfortunately, we are still years away from a cure. Maybe 1 day you can discover the way to cure lung fibrosis!

\section{REFERENCES}

1. Richeldi, L., Collard, H. R., and Jones, M. G. 2017. Idiopathic pulmonary fibrosis. Lancet. 389:1941-52. doi: 10.1016/S0140-6736(17)30866-8

2. Meyer, K. C. 2017. Pulmonary fibrosis, part I: epidemiology, pathogenesis, and diagnosis. Expert Rev. Respir. Med. 11:343-59. doi: 10.1080/17476348.2017. 1312346

SUBMITTED: 13 July 2020; ACCEPTED: 18 May 2021; PUBLISHED ONLINE: 14 June 2021.

EDITED BY: Valeria Costantino, University of Naples Federico II, Italy

CITATION: Boni AJ, Roque W and Romero F (2021) What Happens to the Lungs When They Get Hurt? Front. Young Minds 9:582902. doi: 10.3389/frym.2021. 582902

CONFLICT OF INTEREST: The authors declare that the research was conducted in the absence of any commercial or financial relationships that could be construed as a potential conflict of interest.

COPYRIGHT () 2021 Boni, Roque and Romero. This is an open-access article distributed under the terms of the Creative Commons Attribution License (CC BY). The use, distribution or reproduction in other forums is permitted, provided the original author(s) and the copyright owner(s) are credited and that the original publication in this journal is cited, in accordance with accepted academic practice. No use, distribution or reproduction is permitted which does not comply with these terms.

\section{YOUNG REVIEWERS}

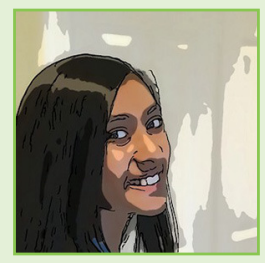

\section{NITYA, AGE: 10}

I love to experiment and try new things in art, crafts, science, and technology. My favorite pastime is to do crafts and TikTok's. My favorite subjects in school are math and science. I like science the most because it teaches me how things work. Basketball is my favorite sport. I would like to be a young reviewer to learn more about how science helps us understand things around us especially the human 

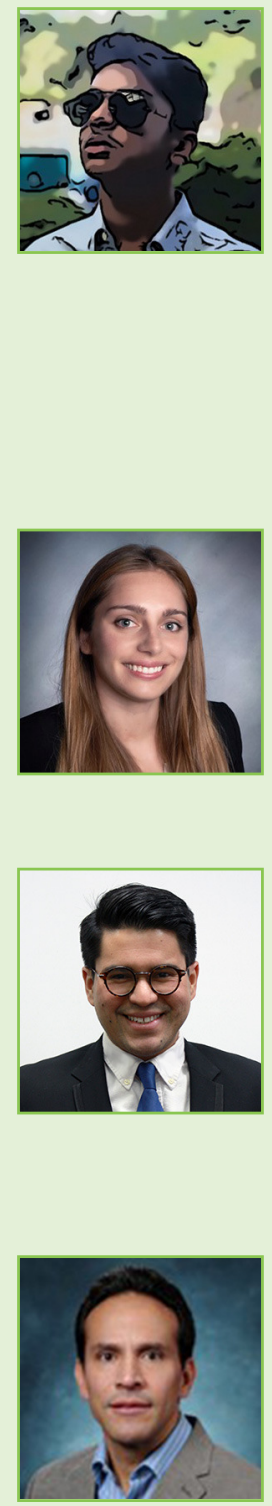

body. I like music and can play instruments, such as piano and saxophone. I am also learning Indian classical vocal music.

\section{SIDHAARTH, AGE: 14}

My favorite subjects in school are math and science. I like biology the most because I enjoy dissections, they give me a hands-on experience to understand the different functions of the body. I like playing basketball and baseball. This opportunity is interesting to me because it will help me to understand different perspectives on many topics in the world. I also like music and can play instruments, such as guitar and saxophone. I am also learning Indian classical vocal music.

\section{AUTHORS}

\section{ALEXANDRA JACQUELINE BONI}

I am a fourth year medical student at Rutgers New Jersey Medical School in Newark, New Jersey and I will become a pediatrician next year. I like studying lung fibrosis because I enjoy learning about how the lungs work. In my free time, I love to play basketball, read books, and watch NFL football (Go Giants!). *ajb311@njms.rutgers.edu

\section{WILLY ROQUE}

I am a third-year internal medicine resident physician at Rutgers New Jersey Medical School. My goal is to become a Pulmonologist and a researcher to help those with lung fibrosis. In my spare time, I enjoy going to the museums/gallery exhibitions, art collecting, and art appreciation. I also take pleasure in long distance biking, training for running races and trekking, and learning new recipes to cook for my friends and family.

\section{FREDDY ROMERO}

I am a researcher who has been studying lung fibrosis for over 20 years. I am interested in finding out what causes lung fibrosis and other lung diseases. I like to play and watch soccer in my spare time. I also enjoy watching movies from Venezuela, where I grew up. 